\title{
IN TRINSIC POINT DEFECTS OF SAMARIUM MONOSULPHIDE CRYSTALS IN METAL PHASE
}

\author{
Ihor Horichok ${ }^{1}$, Myroslava Shevchuk ${ }^{1}$, Taras Parashchuk ${ }^{1, *}$, \\ Mar'jan Galushchak ${ }^{2}$
}

https:

\begin{abstract}
The defective subsystem of samarium monosulphide crystals in metallic phases with different stoichiometric deviation has been investigated. Based on the proposed model of defective subsystem the concentration dependence of samarium monosulphide density has been explained and the temperature dependence of solidus line with metal excess has been determined.
\end{abstract}

Keywords: samarium monosulphide, point defect, solidus line, thermodynamic potential.

\section{Introduction}

Due to a whole set of unique properties [1-3], samarium monosulphide is a promising material for use in many fields of electronics. The main properties are: the tensoresistive effect, the first type isomorphic phase transition "semiconductor-metal" at low pressure, and appearance of the electric voltage after steady heating of the sample in the absence of external temperature gradients.

A wide range of properties is caused by the peculiarities of the material energy structure, and first of all by the presence of narrow energy bands formed by 4 -electrons of metal atoms in a crystal band gap [1,2]. Conduction band of SmS consists of two subzones - zone of light and heavy electrons formed by $6 s$ and $5 d$ orbitals of samarium atom, respectively [4-7]. Valence band is located at $2.3 \mathrm{eV}$ [8] below the bottom of the conduction band, and totally formed by chalcogen orbitals $\left(3 s^{2}\right.$ and $3 p^{4}$ ) [4-6].

Significant influence on the electrical properties of $\mathrm{SmS}$ has their intrinsic point defects. The defects concentration can reach the values of $\approx 10^{21} \mathrm{~cm}^{-3}$. One

\footnotetext{
${ }^{1}$ Vasyl Stefanyk Precarpathian National University,

57, Shevchenko St., 76018 Ivano-Frankivsk, Ukraine;

${ }^{2}$ Ivano-Frankivsk National Technical University of Oil and Gas,

15, Carpathian St., 76001 Ivano-Frankivsk, Ukraine

taras-parashchuk@i.ua

(C) Horichok I., Shevchuk M., Parashchuk T., Galushchak M., 2017
}

should pay attention to the fact, that the region of homogeneity of samarium monosulphide lies entirely on the side of metal excess, the predominant defects can be sulfur vacancies $\mathrm{V}_{\mathrm{S}}$, or anti-structural samarium atoms $\mathrm{Sm}_{\mathrm{S}}[3-8,11]$. However, even now, the region of their dominance or the quantitative correlation between the concentrations of $\left[\mathrm{V}_{\mathrm{S}}\right]$ and $\left[\mathrm{Sm}_{\mathrm{S}}\right]$ are not clearly determined. Often, during the interpretation of the experimental results, in particular [22, 24], the authors use the notion "impurity center" or "compensating center" without distinct determining of their nature. This fact can cause undesirable simplifications of the model. Also, available information about the dominant point defects and the received in this paper results help us to determine the homogeneity boundaries of the compound, because the conduction of the appropriate experiment is complicated by the high melting point of samarium monosulphide $\left(T_{m}=2150 \mathrm{~K}\right.$ [17]).

Aim of the paper is the determination of dependences between point defects concentration (vacancies of sulfur and anti-structural atoms) and temperature, chemical composition and technological factors of two-temperature annealing in the metal vapor of SmS crystals. We paid the main attention to a study of metallic phase of samarium monosulphide in which all point defects, and also f-electrons of Sm atoms are ionized.

The transition between semiconductor and metal phases occurs because of the presence of certain critical concentration of free electrons in the crystal which screens the electric field of the impurity centers. As a result, all linked to them electrons are moving to the conduction band [1]. The concentration of free electrons in the metallic phase is $10^{22} \mathrm{~cm}^{-3}$, and is almost completely determined by samarium atoms ionized by $f$-electrons. Thus, formation of the defect subsystem is strongly influenced by the subsystem of free electrons. And this system is almost not influenced by point defects. This effect is particularly interesting, because it makes possible to find factors influencing the type and concentrations of point defects. 


\section{Experimental}

\subsection{Calculation of Point Defects Concentrations}

Concentrations of point defects in the crystal at temperature $T$ can be determined by minimizing the free energy as a function of the defects concentration [12]:

$$
\mathrm{F}=\mathrm{F}_{0}+\mathrm{F}_{\mathrm{k}}+\mathrm{F}_{\mathrm{el}}
$$

where $F_{0}$ is the free energy that does not depend on the presence of defects, $F_{k}$ is the configuration component of the free energy, $F_{e l}$ is the free energy of the electronic subsystem.

$$
\begin{aligned}
& F_{k} \text { can be represented as: } \\
& \qquad \begin{array}{l}
\mathrm{F}_{\mathrm{k}}=\sum\left(\mathrm{E}+\mathrm{F}_{\mathrm{vib}}\right)[\mathrm{D}]+\sum \mathrm{E}_{\mathrm{J}} \mathrm{N}_{\mathrm{J}}+ \\
+\sum\left(\mathrm{E}_{\mathrm{J}}-\varepsilon_{\mathrm{J}}\right) \mathrm{n}_{\mathrm{J}}-\mathrm{T}\left(\mathrm{S}_{\mathrm{c}}+\mathrm{S}_{\mathrm{a}}\right)
\end{array}
\end{aligned}
$$

where $E$ is the formation energy of point defect; $F_{v i b}$ is the free vibrational energy of the defect; $[D]$ is the concentration of $D$-type defects; $E_{J}$ is the formation energy of samarium ions $N_{J}$ in $J$-th excited state $(J=0,1$, 2 [9]); $n_{J}$ is the samarium ions concentration in the $J$-th state which gave $f$-electron to the conduction band. $S_{c}$ and $S_{a}$ are the configuration entropies of cationic and anionic sublattices.

Entropy is determined by the Boltzmann law:

$$
\mathrm{S}=\mathrm{k} \ln (\mathrm{W})
$$

where $W$ is the thermodynamic probability.

For the cationic and anionic sublattices:

$$
\begin{array}{r}
\mathrm{W}_{\mathrm{c}}=\frac{\mathrm{N}_{\mathrm{c}} !}{\prod\left(\mathrm{N}_{\mathrm{J}}-\mathrm{n}_{\mathrm{J}}\right) ! \prod \mathrm{n}_{\mathrm{J}} !}, \\
\mathrm{W}_{\mathrm{a}}=\frac{\mathrm{N}_{\mathrm{a}} !}{\left(\mathrm{N}-\sum[\mathrm{D}]\right) ! \prod[\mathrm{D}] !}
\end{array}
$$

where $N_{c}$ and $N_{a}$ are the concentrations of nodes in the cationic and anionic sublattice. $N_{J}$ at Boltzmann statistics is defined by the formula:

$$
\mathrm{N}_{\mathrm{J}}=\mathrm{N}_{\mathrm{C}} \frac{(2 \mathrm{~J}+1) \exp \left(-\varepsilon_{\mathrm{J}} / \mathrm{kT}\right)}{\sum(2 \mathrm{~J}+1) \exp \left(-\varepsilon_{\mathrm{J}} / \mathrm{kT}\right)}
$$

where $\varepsilon_{J}$ is the ionization energy of samarium $f$-electron in the $J$-th state; $n_{J}$ is the samarium ions concentration in the $J$-th state, that gave $f$-electron to the conduction band:

$$
\mathrm{n}_{\mathrm{J}}=\frac{\mathrm{N}_{\mathrm{J}}}{1+(2 \mathrm{~J}+1) \exp \left(\frac{-\varepsilon_{\mathrm{J}}+\mu}{\mathrm{kT}}\right)}
$$

where $\mu$ is the electrons chemical potential which we determined from the electroneutrality equation:

$$
\sum \mathrm{Z}[\mathrm{D}]+\sum \mathrm{n}_{\mathrm{J}}=\mathrm{n}_{\mathrm{s}}+\mathrm{n}_{\mathrm{d}}
$$

where $n_{s}$ and $n_{d}$ are the electrons concentration in the $s$ and $d$-conduction band:

$$
\begin{aligned}
& \mathrm{n}_{\mathrm{s}}=\left(\frac{2 \pi \mathrm{m}_{\mathrm{s}}^{*} \mathrm{kT}}{\mathrm{h}^{2}}\right)^{\frac{3}{2}} \mathrm{a} \mathrm{e}^{\mathrm{b} \frac{\mu}{\mathrm{kT}}}, \\
& \mathrm{n}_{\mathrm{d}}=\left(\frac{2 \pi \mathrm{m}_{\mathrm{d}}^{*} \mathrm{kT}}{\mathrm{h}^{2}}\right)^{\frac{3}{2}} \mathrm{a} \mathrm{e}^{\mathrm{b} \frac{\mu-\Delta \mathrm{E}_{\mathrm{C}}}{\mathrm{kT}}}
\end{aligned}
$$

where $a$ and $b$ coefficients are the corrections which take into account the degeneracy of carriers. We calculated these corrections numerically by approximating the Fermi integral. $m_{s}^{*}, m_{d}^{*}$ are the effective mass of electrons in $s$ and $d$ zones, respectively. $\Delta E_{C}$ is the distance between the bottom of $s$ and $d$ bands.

Taking into account the dependences between the effective mass and the electrons concentration in $d$ conduction band, the dependence $m(n)$, received in paper [15], is approximated to the next function:

$$
\frac{\mathrm{m}_{\mathrm{d}}^{*}}{\mathrm{~m}_{0}}=\alpha \mathrm{n}_{\mathrm{d}}^{\beta}=0.2459 \cdot 10^{-6} \cdot \mathrm{n}_{\mathrm{d}}^{\frac{1}{3}}
$$

Considering the last formula:

$$
\mathrm{n}_{\mathrm{d}}=\alpha^{3} \cdot \mathrm{N}_{\mathrm{C}, \mathrm{d}(0)}^{2} \cdot \mathrm{a}^{2} \mathrm{e}^{2 \mathrm{~b} \frac{\mu-\Delta \mathrm{E}_{\mathrm{C}}}{\mathrm{kT}}},
$$

where $\mathrm{N}_{\mathrm{C}, \mathrm{d}(0)}=\left(\frac{2 \pi \mathrm{m}_{0} \mathrm{kT}}{\mathrm{h}^{2}}\right)^{\frac{3}{2}}$.

Free energy of the electron subsystem:

$$
\mathrm{F}_{\mathrm{el}}=\left(\mathrm{n}_{\mathrm{s}}+\mathrm{n}_{\mathrm{d}}\right) \mu
$$

Additionally, we have to take into account the condition:

$$
2\left[\mathrm{Sm}_{\mathrm{S}}^{0}\right]+2\left[\mathrm{Sm}_{\mathrm{S}}^{+}\right]+\left[\mathrm{V}_{\mathrm{S}}^{0}\right]+\left[\mathrm{V}_{\mathrm{S}}^{-}\right]=\mathrm{X}_{\mathrm{Sm}}
$$

where $X_{S m}$ is the concentration of super-stoichiometric samarium atoms.

Presented equations have a general form, and in case of the metallic phase, they will be significantly simpler due to the complete ionization of $f$-electrons. Thus, we didn't consider the influence of the second and third terms in Eq. (2). Thermodynamic probability of cation sublattice equals to one, and entropy, respectively equals to zero, in Eq. (7) the second term on the left side of the sign "=" identically equals to the concentration of samarium atoms $N_{C}$. In Eqs. (2), (7), and (12) we consider only terms that take into account the ionized sulfur vacancies and ionized anti-structural samarium atoms.

\subsection{Concentrations of Point Defects under Samarium Vapor Annealing}

The concentrations of point defects in the crystal at thermodynamic equilibrium with their vapor can be 
determined by solving equations system of equal chemical potentials of components in the vapor $\mu_{i}^{g}$ and in the crystal $\mu_{i}^{s}$ [16]. Under the condition, that at samarium excess the main defects can be sulfur vacancies or antistructural samarium atoms, we obtained:

$$
\begin{array}{ll}
-\mu_{\mathrm{v}_{\mathrm{s}}^{0}}^{\mathrm{s}}=\mu_{\mathrm{s}}^{\mathrm{g}}, & \mu_{\mathrm{Sm}_{\mathrm{s}}^{\mathrm{s}}}^{\mathrm{s}}=\mu_{\mathrm{Sm}}^{\mathrm{g}}-\mu_{\mathrm{s}}^{\mathrm{g}} \\
-\mu_{\mathrm{v}_{\mathrm{s}}^{\mathrm{s}}}=\mu_{\mathrm{s}}^{\mathrm{g}}, & \mu_{\mathrm{Sm}_{\mathrm{s}}^{+}}=\mu_{\mathrm{Sm}}^{\mathrm{g}}-\mu_{\mathrm{s}}^{\mathrm{g}}
\end{array}
$$

Chemical potential of the defect can be determined by differentiation of the free energy (1) by the defects concentration:

$$
\begin{aligned}
& \mu_{D_{i}}=\frac{d F}{d\left[D_{i}\right]}=E_{i}+F_{v i b, i}-k T \ln \left(\frac{N-\sum[D]}{\left[D_{i}\right]}\right)+ \\
& +\left(\left(n_{s}+n_{d}\right)+\left(n_{s}+2 n_{d}\right) \frac{b}{k T} \mu\right) \frac{d \mu}{d\left[D_{i}\right]}
\end{aligned}
$$

For the metallic phase we chose from Eqs. (13)-(14) only that one, which considered the equilibrium of ionized defects (Eq. (14)). The chemical potential of electrons for the metallic phase was determined from Eq. (7):

$$
\mu=\frac{1}{\mathrm{~b}} \mathrm{k} \ln \left(\frac{-\mathrm{B}+\sqrt{\mathrm{B}^{2}+4 \mathrm{~A} \cdot \mathrm{ZZ}}}{2 \mathrm{~A}}\right)
$$

where $A=\left(N_{C, 0}\right)^{2}\left(\frac{6}{10^{5}}\right)^{6} \exp \left(-2 b \frac{\mathrm{dE}_{\mathrm{C}}}{\mathrm{kT}}\right) \cdot \mathrm{a}^{2}$,

$$
\mathrm{B}=\mathrm{N}_{\mathrm{C}, \mathrm{s}} \cdot \mathrm{a}, \mathrm{ZZ}=\mathrm{Z}_{\mathrm{V}_{\mathrm{s}}^{-}}\left[\mathrm{V}_{\mathrm{S}}^{-}\right]+\mathrm{Z}_{\mathrm{Sm}_{\mathrm{s}}^{+}}\left[\mathrm{Sm}_{\mathrm{S}}^{+}\right]+\mathrm{N}_{\mathrm{C}}
$$

We determined the chemical potential of the sulfur and samarium vapors over SmS [17] according to [18]:

$$
\begin{gathered}
\mu^{\mathrm{g}}=\mathrm{kT} \ln \mathrm{P}+\mu_{0} \\
\mu_{0}=\mathrm{kT}\left(-\ln (\mathrm{kT})+\ln \left(\mathrm{h}^{3} /(2 \pi \mathrm{mkT})^{\frac{3}{2}}\right)\right)
\end{gathered}
$$

where $m$ is the mass of the atom.

We considered that the samarium vapor pressure $P_{S m}$ at the limit of $\mathrm{SmS}$ homogeneity approximately equals to the vapor pressure of pure samarium. This approximation is not accurate but is satisfactorily performed for many semiconductor crystals [19].

In the reference data one can find contradictory information about the vapor pressure of samarium over pure samarium [26-28]. On the one hand, in the paper [26] we can find the temperature dependence of pressure $\left(\lg (\mathrm{P})=-\frac{15020}{\mathrm{~T}}+5.50\right)$, which, on the other hand, does not correspond to the pressure values presented in [27] $(P=4.18 \mathrm{~Pa}$ at $T=1072 \mathrm{~K})$ and [28] $(P=7.7 \mathrm{~Pa}$ at $T=1108 \mathrm{~K})$. That's why, it is important to clarify this dependence. According to [29], the temperature dependence of samarium vapor pressure over pure samarium can be determined based on the energy of vaporization:

$$
\mathrm{P}=\int \frac{\mathrm{EdT}}{\mathrm{T}\left(\mathrm{V}_{\mathrm{g}}-\mathrm{V}_{\mathrm{s}}\right)}
$$

Assuming that the evaporation energy weakly depends on the temperature $(E=$ const $)$, and $V_{g} \gg V_{s}$ and $V_{g} P=R T$ :

$$
\lg (\mathrm{P})=-\frac{\mathrm{E}}{2.303 \cdot \mathrm{RT}}+\mathrm{const}
$$

Using the value of evaporation energy $\left(E_{\text {vapor }}(\mathrm{Sm})=\right.$ $=166.6 \mathrm{~kJ} / \mathrm{mol}$ [27]), we obtained the relationship:

$$
\lg (\mathrm{P})=-\frac{8705}{\mathrm{~T}}+\text { const }
$$

Also, by using the known value of samarium vapor pressure at $T=1072 \mathrm{~K}(P=4.18 \mathrm{~Pa})$ [27], one can determine the constant in (22). So:

$$
\lg (\mathrm{P})=-\frac{8705}{\mathrm{~T}}+3.74
$$

that at the same time allows both experimental values of samarium vapor pressure.

In Eqs. (13)-(14), at calculations of point defects concentration, the vapor pressure of sulfur expressed by vapor pressure of samarium, uses the equilibrium constant of the reaction $\operatorname{SmS}(s) \leftrightarrow \mathrm{Sm}(g)+\mathrm{S}(g), \mid K=P_{S m} P_{S}$. The temperature dependence of the constant can be calculated by the following equation [30]:

$$
\mathrm{RT} \lg \left(\mathrm{K}_{\mathrm{P}}\right)=-\Delta_{\mathrm{g}} \mathrm{G}_{\mathrm{T}}^{0}=-\Delta_{\mathrm{g}} \mathrm{H}_{\mathrm{T}}^{0}+\mathrm{T} \Delta_{\mathrm{g}} \mathrm{S}_{\mathrm{T}}^{0}
$$

where $\Delta_{g} G_{T}^{0}$ is the formation thermodynamic potential of substances in the standard state at the given temperature.

The temperature dependences of $\Delta_{g} H_{T}^{0}$ and $\Delta_{g} S_{T}^{0}$ are described by the following equations [30]:

$$
\begin{gathered}
\Delta_{\mathrm{g}} \mathrm{H}_{\mathrm{T}}^{0}=\Delta_{\mathrm{g}} \mathrm{H}_{298}^{0}+\int_{298}^{\mathrm{T}} \Delta_{\mathrm{g}} \mathrm{C}_{\mathrm{p}}^{0} \mathrm{dT} \\
\Delta_{\mathrm{g}} \mathrm{S}_{\mathrm{T}}^{0}=\Delta_{\mathrm{g}} \mathrm{S}_{298}^{0}+\int_{298}^{\mathrm{T}} \frac{\Delta_{\mathrm{g}} \mathrm{C}_{\mathrm{p}}^{0}}{\mathrm{~T}} \mathrm{dT}
\end{gathered}
$$

In the Table one can find thermodynamic parameters of the SmS crystals and vapors of samarium Sm and sulfur S. Samarium in a gas phase is monatomic [26]. Sulfur can easily form the cyclic molecules with a number of atoms from 2 till 12 [27]. One can find that the cycle $S_{8}$ is especially stable, which dominates in a gas phase at $T=423 \mathrm{~K}$. At $T=444.6 \mathrm{~K}$ the dominant molecular cycles are $\mathrm{S}_{8}, \mathrm{~S}_{6}, \mathrm{~S}_{7}$ and little $\mathrm{S}_{2}$; at $873 \mathrm{~K}$ the dominant molecular cycles are $\mathrm{S}_{8}, \mathrm{~S}_{6}, \mathrm{~S}_{7}$ in the equal number amounts and slightly less than $S_{2}$; at $973 \mathrm{~K}$ in about equal amounts $S_{2}, S_{6}$, $\mathrm{S}_{8}, \mathrm{~S}_{7}$, and little $\mathrm{S}_{3}$; above $1003 \mathrm{~K}$ the dominate molecules are $S_{2}$, above $1773 \mathrm{~K}$ - the monatomic molecules [27]. According to the fact that the annealing samarium monosulfide is effective at temperatures $T>1273 \mathrm{~K}$, it is possible to limit the dominance of constants in a couple of monatomic and diatomic molecules. 
Thermodynamic parameters of $\mathrm{SmS}$ crystals and $\mathrm{Sm}, \mathrm{S}$ vapors [26]

\begin{tabular}{|c|c|c|c|}
\hline Substance & $\Delta H_{f}^{0}(298), \mathrm{kcal} / \mathrm{mol}$ & $S^{0}(298), \mathrm{cal} /(\mathrm{mol} \cdot \mathrm{K})$ & $c_{p}^{0}(298), \mathrm{cal} /(\mathrm{mol} \cdot \mathrm{K})$ \\
\hline SmS (crystal) & -103.000 & 24.15 & 13.63 \\
\hline $\mathrm{Sm}_{\text {(vapor) }}$ & 49.400 & 43.72 & 7.26 \\
\hline $\mathrm{S}_{1}$ (vapor) & 65.770 & 40.084 & 5.64 \\
\hline $\mathrm{S}_{2}$ (vapor) & 30.480 & 54.50 & 7.75 \\
\hline
\end{tabular}

In the case of dominance in a couple of monoatomic sulfur molecules, by using the table data, the values $\Delta_{g} H_{298}^{0}, \Delta_{g} S_{298}^{0}$ and $\Delta_{g} c_{p}^{0}$ will be equal:

$$
\begin{gathered}
\Delta \mathrm{H}_{298}^{0}=65.770+49.400-(-103.000)= \\
=218.17(\mathrm{kcal} / \mathrm{mol}) \\
\Delta \mathrm{S}_{298}^{0}=40.084+43.72-24.15=59.654(\mathrm{cal} /(\mathrm{mol} \cdot \mathrm{K})) \\
\Delta \mathrm{c}_{\mathrm{p}, 298}^{0}=5.64+7.26-13.63=-0.73(\mathrm{cal} /(\mathrm{mol} \cdot \mathrm{K}))
\end{gathered}
$$

Further, using the formulas (25-26) and approximation $\Delta c_{p}=$ const:

$$
\begin{gathered}
\Delta \mathrm{H}_{\mathrm{T}}^{0}=\Delta \mathrm{H}_{298}^{0}+\Delta \mathrm{c}_{\mathrm{p}} \cdot(\mathrm{T}-298)=2 \\
=218170+(-0.73)(\mathrm{T}-298)(\mathrm{cal} / \mathrm{mol}) \\
\Delta \mathrm{S}_{\mathrm{T}}^{0}=\Delta \mathrm{S}_{298}^{0}+\Delta \mathrm{c}_{\mathrm{p}, 298} \cdot \ln \left(\frac{\mathrm{T}}{298}\right)= \\
=59.654+(-0.73) \cdot \ln \left(\frac{\mathrm{T}}{298}\right)(\mathrm{cal} /(\mathrm{mol} \cdot \mathrm{K}))
\end{gathered}
$$

We found the constant $K_{p}$ by the formula (24):

$$
\mathrm{K}_{\mathrm{p}}(\mathrm{T})=10^{-\frac{47703}{\mathrm{~T}}+14,096-0.159 \cdot \ln \mathrm{T}}\left(\mathrm{atm}^{2}\right)
$$

In the case of dominaton in the pair of diatomic sulfur molecules $\left(\operatorname{SmS}(s)=\operatorname{Sm}(g)+1 / 2 \mathrm{~S}_{2}(g)\right) \quad$ we calculated $\Delta_{g} H_{298}^{0}, \Delta_{g} S_{298}^{0}$ and $\Delta_{g} c_{p}^{0}$ :

$$
\begin{gathered}
\Delta \mathrm{H}_{298}^{0}=\frac{1}{2} 30.480+49.400-(-103.000)= \\
=167.64(\mathrm{Kcal} / \mathrm{mol})
\end{gathered}
$$

$\Delta \mathrm{S}_{298}^{0}=\frac{1}{2} 54.50+43.72-24.15=46.82(\mathrm{cal} /(\mathrm{mol} \cdot \mathrm{K}))$

$\Delta \mathrm{c}_{\mathrm{p}, 298}^{0}=\frac{1}{2} \cdot 7.75+7.26-13.63=-2.495(\mathrm{cal} /(\mathrm{mol} \cdot \mathrm{K}))$

Then:

$$
\mathrm{K}_{\mathrm{p}}(\mathrm{T})=10^{-\frac{36781}{\mathrm{~T}}+13.877-0.545 \cdot \ln \mathrm{T}}\left(\mathrm{atm}^{2}\right)
$$

\subsection{Energy Parameters of Point Defects}

Required for calculations, the formation energies of vacancies are calculated on the basis of thermochemical data by using the method proposed in [31]:

$$
\mathrm{E}_{0}=\mathrm{E}^{\prime}-\mathrm{E}_{\mathrm{Z}}+\mathrm{E}_{\mathrm{K}}+\Delta \mathrm{E}_{1}+\Delta \mathrm{E}_{2}
$$

We considered the value $E^{\prime}$ to be equal to the atomization energy of the substance (9.45 eB [26]).

$E_{z}$ is the formation energy of new bonds [31]:

$$
\mathrm{E}_{\mathrm{Z}}=\mathrm{x} \cdot \delta_{1}
$$

where $x=12$ is the number of new bonds S-S (for $V_{S m}$ ) or $\mathrm{Sm}-\mathrm{Sm}$ (for $V_{S}$ ), $\delta_{1}$ is the energy of one bond, which equals to the melting energy of pure elements Sm $(0.089$ [26]) or S (0.015 [27]), respectively.

$E_{k}$ in (29) defines the energy of coulomb interaction between the atoms around vacancies:

$$
\mathrm{E}_{\mathrm{K}}=\frac{1}{4 \pi \varepsilon_{0}} \cdot \frac{\mathrm{z}_{\mathrm{A}, \mathrm{B}}^{*} \cdot \mathrm{z}_{\mathrm{A}, \mathrm{B}}^{*}}{\varepsilon \cdot \mathrm{r}}
$$

where $z^{*}$ is the effective charges of atoms, $\varepsilon_{0}$ is the electric constant, $\varepsilon$ is the static dielectric constant (18.0 [33]), $r$ is the distance between atoms of the same sort. Effective charges are determined by ionic data [35]:

$$
\mathrm{z}^{*}=\mathrm{n} \sqrt{\mathrm{i}}
$$

where $n$ is the refractive index, and $i$ is the ionicity [35]:

$$
\mathrm{i}=1-\mathrm{e}^{-0,18 \Delta \mathrm{X}^{2} \frac{\mathrm{v}}{\mathrm{N}}}
$$

where $\Delta X$ is the difference of electronegativity of metal atoms and chalcogen $(1,2[35,34]), v$ is the valence, $N=6$ is the coordination number. Then, $z^{*}=0.70 \mathrm{e}_{0}$. We didn't find the reliable data about the refractive index of $\mathrm{SmS}$, so to calculate the effective charge we used the refractive index of europium monosulfide.

The fourth and fifth terms in (29) are responsible for changing the energy bonds between atoms in the first coordination sphere around vacancy $\left(\Delta E_{1}\right)$ and between atoms of the first and second coordination sphere $\left(\Delta E_{2}\right)$. These values can be shown as Morse potential [31]:

$$
\Delta \mathrm{E}_{1}=\mathrm{x} \cdot \delta_{1}\left\{1-\exp \left[-\sqrt{\beta /\left(2 \cdot \delta_{1}\right)} \cdot\left(\mathrm{r}-\mathrm{r}_{0}\right)\right]\right\}^{2}
$$

where $r_{0}$ is the initial distance between the atoms in the first coordinating sphere $(4.224 \mathrm{~A}), r$ is the relative distance, $\beta$ is the power constant for one type atoms.

$$
\Delta \mathrm{E}_{2}=\mathrm{y} \cdot \mathrm{D}\left\{1-\exp \left[-\sqrt{\alpha /(2 \cdot \mathrm{D})} \cdot\left(\mathrm{d}-\mathrm{d}_{0}\right)\right]\right\}^{2}
$$

where $d_{0}$ is the initial distance between the atoms of the first and second coordination spheres $(2.987 \mathrm{~A}), d$ is the relative distance, $\alpha$ is the power constant for the atoms of 
different types. We determined the bond energy $D$ by dividing the atomization energy of $\mathrm{SmS}$ [26] into the coordination number. The values $r$ and $d$ were determined under the condition of minimum energy of vacancy. Power constants are calculated according to $C_{i j}$ [36] $\left(C_{11}=122 \mathrm{GPa}, C_{12}=11.2 \mathrm{GPa}, C_{44}=22.5 \mathrm{GPa}\right)$ using formulas $\alpha=a / 4\left(c_{11}+3 c_{12}\right), \beta=a / 4\left(c_{11}-c_{12}\right)$ [38].

As the values of atomization energy of $\mathrm{SmS}$ are large, the formation energies of vacancies are quite significant when compared to other semiconductor crystals [38]. For the samarium vacancy we received the value $11.54 \mathrm{eV}$, and for sulfur sulfur vacancy - the value $10.64 \mathrm{eV}$. The distance between atoms in the first coordination sphere varies from $4.33 \mathrm{~A}$ for a defect-free crystal to $4.28 \mathrm{~A}$ in the vacancies vicinity, and for atoms between the first and second sphere these distances are even less. If we neglect the last two terms in (29) (i.e. do not pay attention to the relaxation of lattice in the neighborhood of vacancy) then their formation energies are equal to 11.59 and $10.69 \mathrm{eV}$, respectively. In such a way, the deformations in the neighborhood of vacancy does not overcome $2-3 \%$ and taking into account this effect does not significantly influence the calculation result of the formation energy.

Formation energy of anti-structural defects can be defined as:

$$
\mathrm{E}_{\mathrm{Sm}_{\mathrm{S}}\left(\mathrm{S}_{\mathrm{Sm}}\right)}=\mathrm{E}_{0}-\mathrm{x}_{1} \frac{\mathrm{E}_{\mathrm{at}, \mathrm{Sm}(\mathrm{S})}}{\mathrm{x}_{2}}
$$

where $E_{0}$, as in Eq. (29), is considered to be equal to the atomization energy of samarium monosulphide, $x_{1}$ is the number of bonds between the nearest neighbors in SmS, $E_{a t, \mathrm{Sm}(\mathrm{S})}$ is the atomization energy of pure $\mathrm{Sm}$ or $\mathrm{S}, x_{2}$ is the number of bonds between the nearest neighbors in the structures, which formed pure components. Thus, the formation energy of anti-structural defect is taken as the difference between the energy of one bond of samarium monosulphide and the energy of one individual component bonds (samarium or sulfur) multiplied by the coordination number of SmS.

Calculated by the formula (26) formation energies of anti-structural defects are: $E\left(\mathrm{Sm}_{\mathrm{S}}\right)=6.24 \mathrm{eV}$, $E\left(\mathrm{~S}_{\mathrm{Sm}}\right)=9.31 \mathrm{eV}$, respectively.

The energies of singly ionized donor and acceptor defects were determined in accordance with the formulas:

$$
\mathrm{E}_{1}=\mathrm{E}_{0}-\varepsilon_{1}, \mathrm{E}_{1}=\mathrm{E}_{0}+\varepsilon_{1}
$$

where $E_{0}$ is the formation energy of neutral defect, $\varepsilon_{1}$ is the ionization energy. We considered the anti-structural defect as a shallow donor with an ionization energy $E_{C}-$ $0.045 \mathrm{eV}$ [3], and vacancy of sulfur - as a shallow acceptor with an ionization energy $E_{v}+(\approx 0.1) \mathrm{eV}$ [7].

The free vibrational energy for vacancy [13] will be:

$$
\mathrm{F}_{\mathrm{vib}}=-\left\{3 \mathrm{kT} \ln \left(\frac{\mathrm{T}_{\theta}}{\mathrm{T}}\right)-\mathrm{kT}\right\}+\mathrm{x} \cdot 3 \mathrm{kT} \ln \left(\frac{\omega}{\omega_{0}}\right)
$$

and anti-structural defects will be:

$$
\mathrm{F}_{\mathrm{vib}}=\mathrm{x} \cdot 3 \mathrm{kT} \ln \left(\frac{\omega}{\omega_{0}}\right)
$$

where $x$ is the number of atoms that changed their frequency oscillations from $\omega_{0}$ to $\omega$.

The change of the oscillation frequencies of atoms in the vicinity of the anti-structural defect in $\mathrm{Sm}_{\mathrm{S}}$ [14] will be:

$$
\frac{\omega}{\omega_{0}}=\frac{\mathrm{T}_{\mathrm{Sm}} \theta_{\mathrm{SmS}}}{\mathrm{T}_{\mathrm{Sms}} \theta_{\mathrm{Sm}}}
$$

where $T_{\mathrm{Sm}}$ and $T_{\mathrm{SmS}}$ are the melting temperatures; $\theta_{\mathrm{Sm}}$, $\theta_{\mathrm{Sms}}$ are the Debye temperatures for samarium and monosulphide samarium crystals. We considered the value $\omega / \omega_{0}$ as the variational parameter for sulfur vacancy.

As a result of calculations of the atoms oscillations frequency in the vicinity of anti-structural defects using expression (40) we obtained the value $\omega / \omega_{0}=1.13$. Thus, $\mathrm{Sm}_{\mathrm{S}}$ does not change the oscillation frequency of the surrounding atoms. For sulfur vacancies the value $\omega / \omega_{0}$, determined by fitting the maximum theoretically calculated solidus line (Fig.

\section{Results and Discussion}

The calculation procedure of the defects concentrations using received equations is realized numerically by the program MAPLE. For this, we used the methods of random perturbation for finding the function minimum (2) and the method of penalty functions for accounting the additional condition (2). The solution of equations of chemical potentials equality (13-14) is performed by minimizing a quadratic function of the residuals.

From the analysis of the calculated values of the formation energies of the defect we can assume that the concentration of vacancies should be much less than the concentration of anti-structural defects because the numerical values of formation energies $E$ of these defects twice differ. However, according to the calculation results presented in Fig. 1 the concentration $\left[\mathrm{V}_{\mathrm{S}}^{-}\right]$is lower, comparable with the concentration $\left[\mathrm{Sm}_{\mathrm{S}}^{+}\right]$. Concentration of sulfur vacancies and anti-structural samarium atoms increases with increasing the content of overstoichiometric samarium. However, the concentration increase of the last ones is slower. This change in the correlation between point defects determines the 
nonlinearity of the concentration dependence of samarium monosulphide density (Fig. 1b): at low content of excess samarium, the increase in density is caused by increasing anti-structural defects concentration and the concentration of vacancies at this change has almost no effect. While further increasing the content $\mathrm{Sm}$, the concentration of sulfur vacancies is of the same order of magnitude as the concentration of anti-structural defects and the density growth of SmS are changed slowly.

Density was determined by the formula:

$$
\rho=\frac{4}{\mathrm{a}^{2}} \mathrm{M}_{\mathrm{Sm}}+\left[\mathrm{Sm}_{\mathrm{S}}^{+}\right]\left(\mathrm{M}_{\mathrm{Sm}}-\mathrm{M}_{\mathrm{S}}\right)+\frac{4}{\mathrm{a}^{2}} \mathrm{M}_{\mathrm{S}}-\left[\mathrm{V}_{\mathrm{S}}^{-}\right] \mathrm{M}_{\mathrm{S}}
$$

For finding the boundaries of the $\mathrm{SmS}$ homogeneity region on the side of metal excess we made a calculation of point defects concentration under equilibrium conditions with a metal vapor. We established that the annealing in $\mathrm{Sm}$ vapor leads to significant restructuring of crystal defect subsystem of SmS metallic phase. The dominant defects inder these conditions are

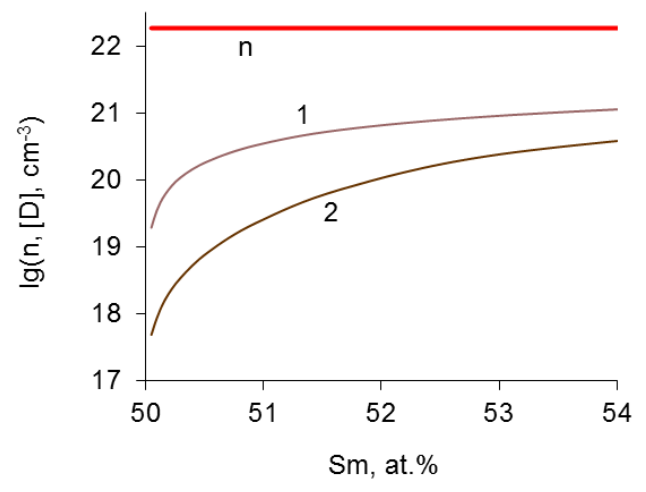

a) sulfur vacancies (Fig. 2a), which determine the temperature dependence of the solidus line on the excess metal side (Fig. 2b). The concentration of anti-structural defects in this case is much lower.

Calculated samarium monosulphide solidus line on the metal excess side has the retrograde nature, and its temperature dependence provides maximum solubility of samarium at temperature $T \approx 1700 \mathrm{~K}$.

Relatively high concentrations of sulfur vacancies can be explained by the fact that at creating the vacant levels near the top of the valence band, the chalcogen vacancies are the traps for free electrons that are falling from the bottom of the conduction band to the localized vacancies levels $V_{S}$, and causing an increase in the magnitude of the crystal free energy at the value close to a band gap value $(\approx 2.3 \mathrm{eV})$. Significant concentrations of electrons in the metallic phase cause the sulfur vacancies formations, because they lead to the significant gains in the total energy of the crystal.

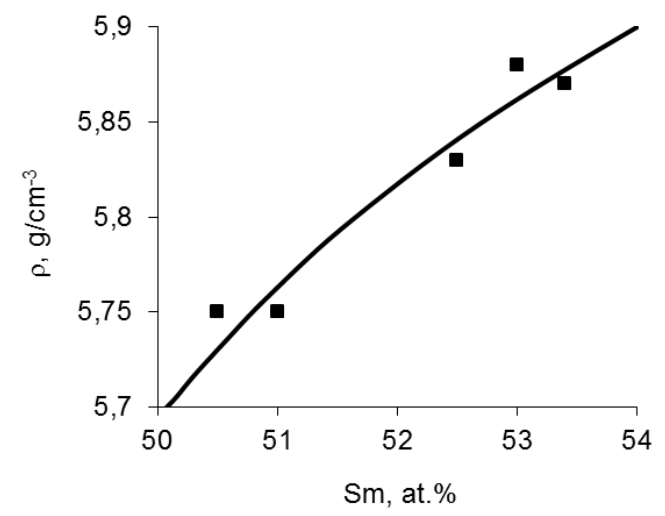

b)

Fig. 1. The concentration dependences of electrons density $n,\left[\mathrm{Sm}_{\mathrm{S}}^{+}\right](1),\left[\mathrm{V}_{\mathrm{S}}^{-}\right]$(2) point defects (a) and density (b) on Sm content in the metallic phase of samarium monosulphide

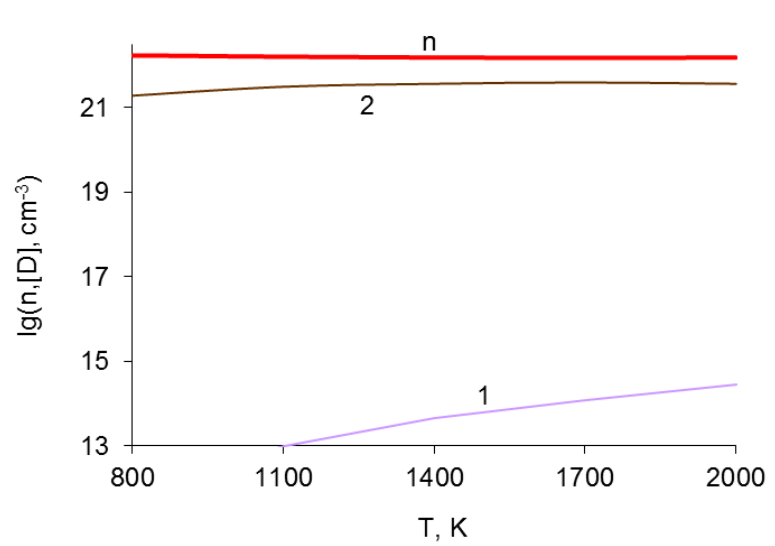

a)

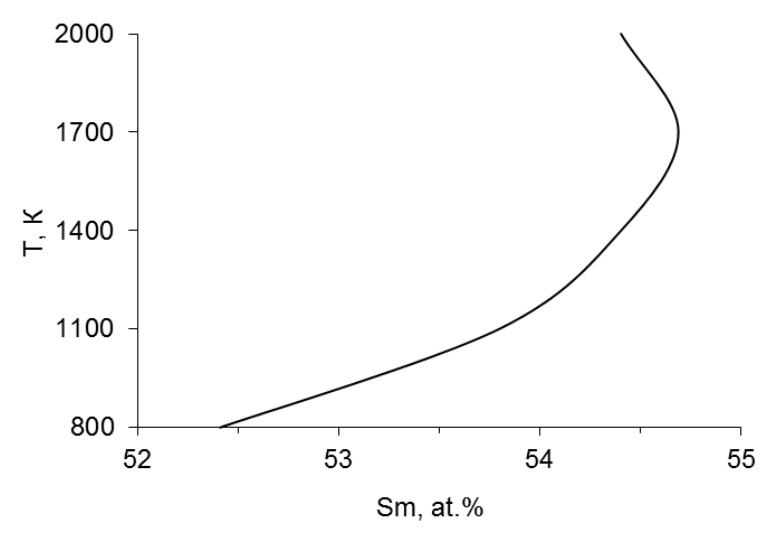

b)

Fig. 2. The temperature dependence of the electrons concentration $n$ and $\left[\mathrm{Sm}_{\mathrm{S}}^{+}\right](1)$, and $\left[\mathrm{V}_{\mathrm{S}}^{-}\right]$(2) point defects in $\mathrm{SmS}$ under two-temperature annealing at the maximum vapor pressure of samarium (a) and temperature dependence of the samarium monosulphide solidus line on a metal excess (b) 


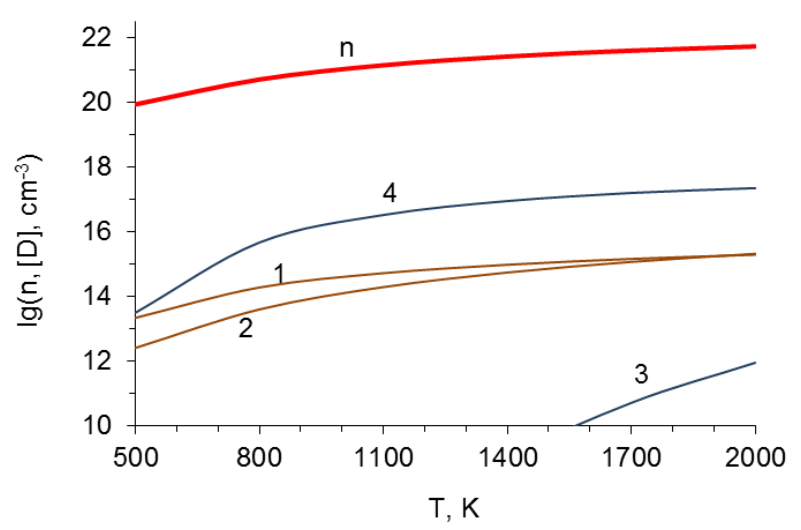

a)

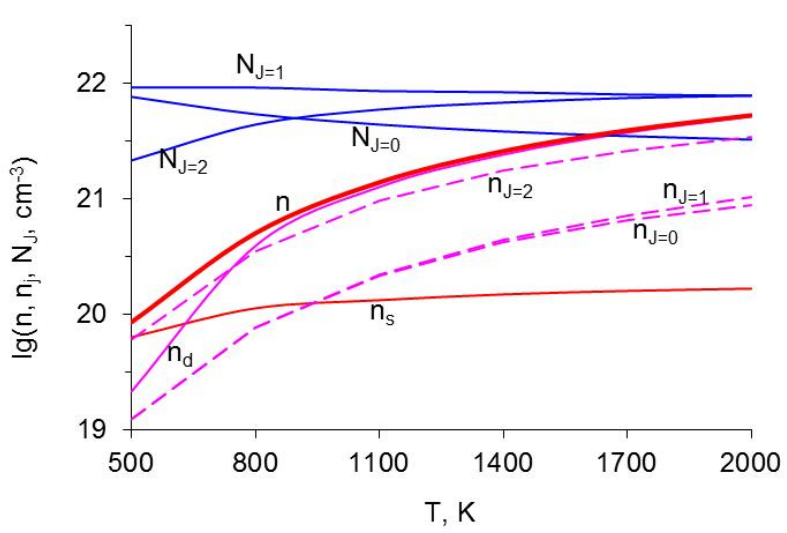

b)

Fig. 3. The temperature dependences of the electron concentration $n,\left[\mathrm{Sm}_{\mathrm{S}}^{0}\right](1),\left[\mathrm{Sm}_{\mathrm{S}}^{+}\right](2),\left[\mathrm{V}_{\mathrm{S}}^{0}\right](3)$

and $\left[\mathrm{V}_{\mathrm{S}}^{-}\right]$(4) point defects (a), and also concentrations of the electrons in subzones $\left(n_{s}, n_{d}\right)$, the concentration of samarium ions

in the $J$-th state $\left(N_{J}\right)$ and samarium ions which give $f$-electrons into the conduction band when being in the J-th state $\left(n_{J}\right)(\mathrm{b})$ in the semiconductor phase of $\mathrm{SmS}$ under two-temperature annealing at the maximum pressure of a samarium vapor

To ensure that even under domination of the sulfur vacancies, which are the acceptors and can significantly reduce the concentration of free electrons, the crystal does not transform into the semiconductor phase, we spent modeling of the defect subsystem with the subsequent calculation of the free electrons concentration especially for the semiconductor phase. The critical value of the electron concentration $n_{c}$, at which the phase transition is possible, was calculated using the correlation [1]:

$$
\mathrm{n}_{\mathrm{C}}^{\frac{1}{3}} \mathrm{a}_{\mathrm{B}}=0.25
$$

where $\mathrm{a}_{\mathrm{B}}=\varepsilon_{\infty} \mathrm{h}^{2} /\left(\mathrm{m}^{*} \mathrm{e}^{2}\right)$ is the Bohr radius, $\varepsilon_{\infty}$ is the dielectric permittivity $\left(\varepsilon_{\infty}=18[9]\right), m^{*}$ is the effective mass of the electron. If $m^{*} \approx m_{0}$ the critical concentration equals to $\approx 10^{20} \mathrm{~cm}^{-3}$.

Due to the complexity of determining the concentration of point defects in the semiconductor phase for the above scheme, firstly, using Eq. (13), we obtained analytical expressions for the concentrations of neutral defects:

$$
\begin{array}{r}
{\left[\mathrm{V}_{\mathrm{S}}^{0}\right]=\mathrm{N}_{\mathrm{J}} \cdot \frac{\mathrm{P}_{\mathrm{Sm}}}{\mathrm{K}} \cdot \exp \left(-\frac{\mu_{0, \mathrm{~S}}^{\mathrm{g}}}{\mathrm{kT}}\right) \cdot \exp \left(-\frac{\mathrm{E}_{\mathrm{v}_{\mathrm{s}}^{0}}+\mathrm{F}_{\mathrm{vib}, \mathrm{V}_{\mathrm{s}}^{0}}}{\mathrm{kT}}\right)} \\
{\left[\mathrm{Sm}_{\mathrm{S}}^{0}\right]=\mathrm{N}_{\mathrm{J}} \cdot \frac{\left(\mathrm{P}_{\mathrm{Sm}}\right)^{2}}{\mathrm{~K}} \cdot \exp \left(\frac{\mu_{0, \mathrm{Sm}}^{\mathrm{g}}-\mu_{0, \mathrm{~S}}^{\mathrm{g}}}{\mathrm{kT}}\right) .} \\
\mid \cdot \exp \left(-\frac{\mathrm{E}_{\mathrm{Sm}_{\mathrm{s}}^{0}}+\mathrm{F}_{\mathrm{vib}, \mathrm{Sm}_{\mathrm{s}}^{0}}}{\mathrm{kT}}\right)
\end{array}
$$

and to determine the concentration of ionized defects we used next dependences:

$$
\begin{aligned}
& {\left[\mathrm{V}_{\mathrm{S}}^{-}\right]=\left[\mathrm{V}_{\mathrm{S}}^{0}\right] \exp \left(-\frac{\varepsilon_{1}-\mu}{\mathrm{kT}}\right),} \\
& {\left[\mathrm{Sm}_{\mathrm{S}}^{+}\right]=\left[\mathrm{Sm}_{\mathrm{S}}^{0}\right] \exp \left(\frac{\varepsilon_{1}-\mu}{\mathrm{kT}}\right)}
\end{aligned}
$$

The above Eq. (45) was solved by including an electroneutrality Eq. (7) in the system. The value $\varepsilon_{1}$ in (45) is the ionization energy of the defect, and the electron chemical potential $\mu$ was determined numerically from the equation of electroneutrality (7). The ionization energies of $f$-electrons are taken from Ref. [13], according to which the energy structure of samarium monosulphide has to consider the main $f$-electron level $\left(J=0, E_{c}=-0.23 \mathrm{eV}\right)$, the first excited level $\left(J=1, E_{c}=-0.19 \mathrm{eV}\right)$ and the second excited level $(J=2)$, which is splitted by a crystal field into five separate levels $\left(E_{c}=-0.1164,-0.1125\right.$, $0.1030,-0.099$ and $-0.090 \mathrm{eV})$.

Thus, according to the calculation results (Fig. 3), the concentration of ionized sulfur vacancies in a semiconductor phase is lower compared to the metallic phase, but $V_{s}^{-}$still remains to be the dominant defects. The concentration of free electrons at the temperature region $T \approx 500 \mathrm{~K}$ is $n \approx n_{c}$ and at higher temperatures it greatly exceeds the critical value. Thus, we can assume that under high temperature equilibrium conditions of $\mathrm{SmS}$ with a metal pair the crystal will be in the metallic phase.

\section{Conclusions}

1. Using minimization of the thermodynamic potential of the crystal as a function of the concentration 
of defects we calculated the dependences of the concentrations of sulfur vacancies and the concentrations of anti-structural samarium atoms from the temperature and from the chemical composition of the $\mathrm{SmS}$ metallic phase. It was found that the concentration of sulfur vacancies is by 1-2 order lower than the concentration of anti-structural samarium atoms.

2. Based on the received dependences between point defects concentration and chemical composition of crystals we explained the nonlinear growth of $\mathrm{SmS}$ density with the increasing of samarium atoms content in the range from 0.5 till 4.0 at. \% of Sm.

3. Using the method based on the equations solution of equal chemical potentials in a multicomponent heterophase system, we determined the concentrations of point defects in a samarium monosulphide at twotemperature annealing in the samarium vapor. We established that the predominant type of intrinsic point defects in SmS crystals annealed at the maximum vapor pressure of the metal in the temperature range of 1000$2000 \mathrm{~K}$ is singly ionized sulfur vacancies for both semiconductor and metallic phases.

4. Theoretically calculated samarium monosulphide solidus line from the metal side has the retrograde character, and the maximum width of the SmS homogeneity region depends on the temperature $1700 \mathrm{~K}$.

\section{References}

[1] Golubkov A., Goncharova E., Zhuze V. et al.: Fizicheskye Svojstva Halkogenidov Redkozemelnyh Elementov. Nauka, Leningrad 1973.

[2] Ulashkevich Y., Kaminski V., Golubkov A.: Semiconductors, 2009, 43, 324. https://doi.org/10.1134/S1063782609030087

[3] Kaminsky V., Golubkov A., Vasiliev L.: Phys. Solid State, 2002, 44, 1574. https://doi.org/10.1134/1.1501362

[4] Soldatov A., Alperovitch G., Gusatinsky A.: Phys. Solid State, 1985, 27, 1237.

[5] Farberovich O.: Phys. Solid State, 1979, 21, 3434.

[6] Masyukova N..: Phys. Solid State, 1993, 35, 138.

[7] Shadrichev E., Parfen'eva L., Tamarchenko V.: Phys. Solid State, 1976, 18, 2380.

[8] Holubkov A., Goncharov E., Kapustin V. et al.: Phys. Solid State, 1980, 22, 3561.

[9] Kaminskyy V., Vasilyev L.: Phys. Solid State, 2008, 50, 713. https://doi.org/10.1134/S1063783408040197

[10] Kaminskyy V., Sharenkova N., Vasiliev L., Solovyov S.: Phys. Solid State, 2005, 47, 217. https://doi.org/10.1134/1.1866396

[11] Vasiliev L., Kaminskyy V.: Phys. Solid State, 1994, 36, 1172.

[12] Bulyarian S., Svetuhin V., Lions P.: Semiconductors, 2000, 34, 385.

[13] Levich V.: Kurs Teoretycheskoy Fiziky. Nauka, Moskva 1969. [14] Svetuhin V., Bulyarsky S., Sanchischin D.: Lett. J. Appl. Phys., 2004, 30, 9 .

[15] Freik D., Gorichok I., Shevchuk M.: Phys. Chem. Solids, 2012, 13, 27.

[16] Medvedev S.: Fizika i Khimiya Soedineniy $\mathrm{A}^{\mathrm{II}} \mathrm{B}^{\mathrm{VI}}$. Mir, Moskva 1970.
[17] Gordienko S., Fenochka B., Viksman G.: Termodynamica Soedineniy Lantanoidov: Spravochnik. Naukova Dumka, Kiev 1979.

[18] Rumer Y.: Termodynamica, Statystycheskaya Fizika i Kinetyka. Nauka, Moskva 1972.

[19] Zlomanov V., Novoselova A.: P-T-x Diagramy Sostoyanyj Sistemy Metal-Halkogen. Nauka, Moskva 1987.

[20] Knunyants I.: Khimicheskaya Encyclopedia. Sovetskaya entsyclopedia, Moskva 1988.

[21] Zakharov I., Nikitayev A., Prostov V., Purmal A.: Khimicheskaya Entsyklopediya (Problemy, Prymery, Zadaniya), MFTI, Moskva 2000.

[22] Ariponnammal S., Chandrasekaran S.: J. Nano- Electron. Phys., $2011,3,529$.

[23] Suryanarayanan R., Smirnov I., Brun G., Shulman S.: J. de Physique, $\quad 1976, \quad 37, \quad 271$. https://doi.org/10.1051/jphys:01976003703027100

[24] Daoudi E.-F., Kaaouachi A., Hassan S. et al.: Int. J. Comp. Appl., 2013, 67, 23.

[25] Rogers E., Smet P., Dorenbos P., Van der Kolk E.: J. Phys. Condens. Mater., 2010, 22, 47. https://doi.org/10.1088/0953$8984 / 22 / 1 / 015005$

[26] Gordienko S., Fenochka B., Viksman G.: Thermodynamica Lantanojidnuh Spoluk: Dovidnyk. Nauka, Kyiv 1979.

[27] Knuniants I.: Khimicheskaya Entsyklopediya. Sovetskaya entsuklopediya, Moskva 1988.

[28] Jatsenko S., Fedorov E.: Redkozemelnye Elementy. Vzaimodejstvye s p-Metallamy. Nauka, Moskva 1990.

[29] Medvedev S.: Vstuplenye k Poluprovodnykovym Materialam. Vysshaya shkola, Moskva 1970.

[30] Prostov V. (Ed.): Khimicheskaya Termodynamika. Mir, Moskva 2000.

[31] Werner V., Nichugovski D.: Phys. Solid State, 1973, 15, 2012.

[32] Chatterje A., Singh A., Jayaraman A.: Phys. Rev. B, 1972, 2285. https://doi.org/10.1103/PhysRevB.6.2285

[33] Kaminski V., Vasiliev L.: Phys. Solid State, 2008, 50, 685. https://doi.org/10.1134/S1063783408040197

[34] Radzikovskaia S., Marchenko V.: Sulfides of Rare Earth Metals and the Actinide. Naukova Dumka, Kiev 1966.

[35] Batsanov S.: Strukturnaya Khimiya: Zavisimosti i Fakty: Dialog MGU, Moskva 2000.

[36] Kaminski V., Kapustin V. and Smirnov E.: Phys. Solid State, 1980, 22, 3568.

[37] Burenkov U., Nikanorov S.: Phys. Solid State, 1984, 26, 3224. [38] Gorichok I.: Phys. Solid State, 2012, 54, 1459. https://doi.org/10.1134/S1063783412070165

Received: M arch 30, 2016 / Revised: August 25, 2016 / Accepted: J anuary 15, 2017

\section{ВНУТРІШНІ ТОЧКОВІ ДЕФЕКТИ КРИСТАЛІВ МОНОСУЛЬФІДУ САМАРІЮ У ФАЗІ МЕТАЛУ}

Анотація. Досліджено дефектну підсистему кристалів моносульфіду самарію в металевих фазах з різним стехіометричним відхиленням. На основі запропонованої моделі дефектної підсистеми встановлено концентраційну залежність густини моносульфіду самарію $i$ визначено температурну залежність лінії солідусу з надлишком металу.

Ключові слова: моносульфід самарію, точковий дефект, лінія солідусу, термодинамічний потенціал. 